the greatest investigator of the deep and the highest authority on all that concerns the science of the sea-would seem to require no more in the way of review and recommendation than the mention of that fact. Yet it may be well to state that within the compass of 256 pages of thirty lines each we have perhaps the most concise and the most scientific account of this immense subject that has yet been written, set forth in language that the reader most unfamiliar with the subject can grasp with perfect facility. In being, alas! the final contribution to science, we helieve, from John Murray's pen, it is sadly appropriate as a summing up of the work to which his long, arduous, and brilliant scientific life was devoted. Its various chapters deal with the methods and instruments of deep-sea research, the depths of the ocean, the physical characters of its waters, oceanic circulation, life in the ocean, marine deposits, and the geospheres. A glossary, a concise bibliography, and a sufficient index close the volume. It is more fully illustrated than most of its predecessors. There are twelve plates, of which six are coloured maps by Bartholomew of wonderful clearness notwithstanding their size, showing the deeps, the salinity, the surface temperatures, the currents, the surface density, and the deposits of the ocean.

\section{THE ADMINISTRATIVE PROBLEM OF SLEEPING SICKNESS.}

THE Report of the Inter-Departmental Com1 mittee on Sleeping Sickness (Cd. 7349, price $3^{d}$.), recently published, is a most valuable summary of present knowledge on the subject. The committee have taken the evidence of all the leading authorities on the subject, both British and foreign, and the enormous mass of evidence put before them (printed separately as Cd. 7350) has been very carefully sifted and analysed in the Report, which is signed by all members of the committee with certain reservations by two of them (Dr. W. A. Chapple, M.P., and Mr. J. Duncan Millar, M.P.), who have appended a separate memorandum embodying their opinions with regard to the game question.

The following are some of the opinions or recommendations expressed by the committee with regard to controversial questions either of scientific knowledge or practical administration.

The problems which arise with regard to trypanosomiasis in man in Nyasaland and Rhodesia are wholly distinct from the problems which arise in Uganda. Nyasaland trypanosomiasis is caused by $T$. rhodesiense and conveyed by Glossina morsitans; it is a very small factor in the general bill of mortality; it is probably an old and endemic disease, and there appears to be no evidence to indicate that it is likely to become epidemic. On the other hand, Uganda trypanosomiasis is caused by $T$. gambiense and conveyed by $G$. palpalis; it has been known on the west coast of Africa for at least one hundred years, but was first introduced into Uganda at the end of the last century, probably by infected native porters coming from the Congo, and it is believed to have destroyed about 200 , 000 natives between 1898 and 1906 . There is a general agreement among experts that Uganda trypanosomiasis is not endemic beyond the range of $G$. palpalis. $T$. rhodesiense infection is much more virulent than $T$. gambiense infection. All authorities believe the diseases to be distinct, though allied.

The committee considers that the elimination of Glossina as the carrier must be the principal object of all efforts to check or get rid of the disease. The evidence all points to the conclusion that if the tsetse-fly could be eliminated or removed from contact from human settlement, sleeping sickness would practically disappear, infection conveyed by other flies being a negligible factor in the spread of the disease. For this reason the committee attach great importance to a proper and sufficient equipment of entomological research into the bionomics of the incriminated tsetse-flies. This form of research has, in their view, been insufficiently pursued up to the present time. In this form of research there is a large element of chance; accident may at any time lay bare a result which may lead to the solution of the problem, and the multiplication of the workers is the multiplication of chances.

With regard to the vexed question of the reservoir and the advisability or otherwise of gamedestruction:-(I) As regards Uganda trypanosomiasis, there is abundant evidence that human beings, infected but able to get about, serve as reservoirs of the virus, maintaining the endemicity of the disease, and that they may in travelling distribute it widely. There is also evidence that in the absence of men wild animals may be a source of the virus. It is doubtful how much importance should be attached to the antelope as a reservoir of $T$. gambiense. The part this reservoir plays is probably small in comparison with infected man, and to a less extent his domestic animals; for cattle, sheep, and goats have been known to harbour this trypanosome and take no harm.

(2) As regards Nyasaland trypanosomiasis, the committee consider the identity of $T$. rhodesiense with the similar trypanosome found in game, in the same districts, as unproven. The wild animals in question are undoubtedly reservoirs of the trypanosomes pathogenic to stock; but the evidence is conflicting as to whether the wild animals which are a reservoir of the disease affecting domestic stock are a danger to man. Knowledge of the disease, its cause, and its remedies, is still in the making, and hasty and imperfectly considered action of a drastic character such as the attempt to effect a general destruction of wild animals is not justified by the evidence before the committee. In Nyasaland and Rhodesia the incidence of the disease on the population is slight and it is not increasing.

The proposed experiment of removal of wild

NO. 2336 . VOL. 93] 
animals from a selected area may produce valuable results, both as regards knowledge of the habits of the fly, and as to the extent to which the infectivity of the fly and subsequently the infection of man or stock is derived from wild animals. The result of this experiment cannot be confidently anticipated, but, nevertheless, the committee think there is sufficient to justify an expectation of useful results and recommend that if a suitable locality can be found where an experiment can be carried out at a reasonable cost, it should be undertaken.

\section{RECENT STUDIES OF THE ATMOSPHERE.1}

THE German Meteorological Society offered a prize for the best essay on the results of the International Kite and Balloon ascents, and the prize was won by Mr. Gold in I9I 2 by the memoir which is now published by the Meteorological Office. The results mostly refer to ascents which took place prior to December, I909, but in the case of some stations observations are included up to November, I9I I. From an exhaustive consideration of the temperature in the free air and its relation to pressure at sea-level, geographical position, and season, it appears that in Europe August is, in general, the warmest month in the troposphere, and March the coldest, except close to the surface; thus, the temperature lag is greater for the minimum than for the maximum, which, as is pointed out in the memoir, is to be expected, for convection can carry warmth upwards, but not cold. It has become apparent from the study of the upper air that a cyclone is colder than an anticyclone, and this is borne out by Mr. Gold's figures; he finds that a cyclone is colder than an anticyclone up to ten kilometres, that is, up to the level of the stratosphere.

The height at which the stratosphere is found, and its temperature, are known to vary with the surface pressure; the higher the pressure the higher is the lower limit of the stratosphere and the lower the temperature of the layer. Mr. Gold has investigated this point in detail and gives diagrams showing the changes in the stratosphere in height and in temperature through areas of high and low pressure, both in winter and summer. The places where sounding balloons fall show that the general drift of the wind over Europe is from the north-west in the upper air. Balloons sent up in easterly winds usually fall to the east of the starting place in winter, showing that at this season an easterly current is shallow, the pressure gradient above being reversed by the gradient of temperature from south to north. Mr. Gold discusses many questions of the winds and the dynamics of the atmosphere, but it is impossible

1 Geophvsical Memoirs (Meteorological Office) :-

No. 5. The International Kite and Balloon Ascents, By Ernest Gold. (rgr3.) Price is. 6d.

No. 6. The Free Atmosphere in the Region of the British Isles (Third Report). The Calibration of the Balloon Instruments and the Reading of the Traces. By W. H. Dines, F.R.S. (I9r4.) Price id.

No. 7. A Comparison of the Electrical Conditions of the Atmosphere at Kew and Eskdalemuir. By Gordon Dobson. (Igr4) Price 8d.

No. 8. Lag in Marine Barometers on Land and Sea. By Dr. Charles Chiree, F.R.S. (1914.) Price $4 d$.

$$
\text { NO. } 2336 \text {, VOL. 93] }
$$

in a short notice even to indicate every point in the work; it should be read by all interested in dynamical meteorology.

Almost all the observations in the upper air in this country are made with Mr. W. H. Dines's light meteorograph. In Geophysical Memoir, No. 6, Mr. Dines describes very fully the method of calibrating, preparing the instrument for the ascent, and working up the trace. With these instructions and those given in a former publication of the Meteorological Office (M. O. 202) an observer should be able to use the instrument to full advantage

Electrical observations of the atmosphere at the new observatory at Eskdalemuir are discussed by Mr. Dobson in the Geophysical Memoirs, and compared with those at Kew. Conditions differ in several respects, being far more disturbed at the northern station. The diurnal curves of the potential gradient for the two stations are similar during the winter, but differ markedly in the summer; at this season the potential at Eskdalemuir is high at night and begins to fall in the early morning when it is rising to a maximum at Kew. The mean absolute value of the potential gradient is always higher at Kew than at Eskdalemuir, which Mr. Dobson attributes chiefly to the abnormally low conductivity of the air at Kew. The small and uncertain difference in the number of ions between summer and winter at Eskdalemuir is remarkable. The station has not been long established, and the account given in this memoir will, no doubt, be amplified when a longer series of observations from Eskdalemuir is available.

The constriction in the tube of the marine barometer, made to avoid oscillations of the mercury, causes a lag which is discussed by Dr. Chree in No. 8 of the Geophysical Memoirs. The theory was considered by Stokes, who found that the marine barometer had a certain "lagging time." If the sluggishness were due to the constriction alone the lag should be too small to affect readings in practice. But Dr. Chree has investigated the problem by the consideration of the readings of a number of barometers tested at Kew, and finds the lag to be considerably greater than according to Stokes's formula. Further observations with the same result were made with two barometers which were subsequently put on board ship, and read every four hours by the ship's officers during a number of voyages across the Atlantic; the lag at sea was found to be much less than on land, and was almost entirely confined to cases where the barometer was "pumping." No explanation is put forward to account for "the extraordinary difference between land and sea results." Dr. Chree is not of opinion that it can be explained by uncertainties of reading at sea. Further observations are hinted at. and it is certainly desirable to find out why on land the lag should be "enormously greater" than given by Stokes's formula, while at sea it is "exceedingly small." 